\title{
Effects of POE and Carbon Black on the PTC Performance and Flexibility of High-Density Polyethylene Composites
}

\author{
Feng Xue $\mathbb{D}^{\text {, }}$, Kangcai Li $\mathbb{D}$, Lei Cai, and Enyong Ding $\mathbb{C}$ \\ College of Material Science and Engineering, South China University of Technology, Guangzhou 510640, China \\ Correspondence should be addressed to Feng Xue; psfxue@scut.edu.cn
}

Received 19 July 2021; Revised 28 October 2021; Accepted 30 October 2021; Published 10 November 2021

Academic Editor: Szczepan Zapotoczny

Copyright (C) 2021 Feng Xue et al. This is an open access article distributed under the Creative Commons Attribution License, which permits unrestricted use, distribution, and reproduction in any medium, provided the original work is properly cited.

\begin{abstract}
High-density polyethylene (HDPE)/carbon black (CB) is widely used in positive temperature coefficient (PTC) composites. In order to expand its applications to fields that need good flexibility, polyolefin elastomer (POE) was incorporated into HDPE/CB composites as a secondary thermoplastic elastomer phase to provide flexibility. The effects of POE and CB content on the PTC performance and flexibility were investigated. Micro morphology and crystallization behavior are closely related to PTC properties. SEM was conducted to reveal phase morphology and filler dispersion, and DSC was conducted to research crystallization behavior. The results show that the incorporation of $18 \mathrm{wt} . \%$ POE can decrease the percolation threshold of conductive carbon black from $22.5 \mathrm{wt} . \%$ to $16 \mathrm{wt} . \%$. When the CB content is $30 \mathrm{wt} . \%$, the room temperature resistivity gradually increases with the increasing content of POE because of the barrier effect of POE phase, and the PTC intensity is gradually enhanced. Meanwhile, the PTC switching temperature shifts down to a lower temperature. The incorporation of $18 \mathrm{wt} . \%$ POE significantly increases the elongation at break, reaching an ultrahigh value of $980 \mathrm{wt} . \%$, which means great flexibility has been achieved in HDPE/POE/CB composites. This work provides a new method of fabricating PTC composites with balanced electrical and mechanical properties.
\end{abstract}

\section{Introduction}

In general, conductive polymer composites (CPCs) exhibit a sharp electrical resistivity increase when the temperature is close to the melting point of the polymer, which is called the positive temperature coefficient (PTC) effect [1]. As early as the 1950s, the PTC effect was found in carbon black-filled polyolefin composites, which was first suggested by Frydman to be used in electrical circuit protection, selfregulating heaters, and temperature sensors [1]. Up to now, they are still widely used in these fields [2-9]. Besides, some are seen in safety batteries $[2,10,11]$. Lithium-ion batteries are the dominant type of battery used in portable electronic devices, electric vehicle, and large-scale energy storage system for their high-energy density, long cycle life, and fast charging and discharging rate [12]. Under low temperature, batteries suffer from poor performance such as low charging and discharging rate and low charge and discharge capacity [13]. A heating system is necessary for thermal management
[14]. PTC composites are expected to be the heating material with great development potential.

High-density polyethylene (HDPE)/carbon black (CB) is one of the most used conventional PTC composites for its semicrystalline nature, good thermal stability, high thermal expansion rate around the melting point, and notable PTC behavior [9]. However, it is well known that the incorporation of rigid fillers into polymers will increase their brittleness. When HDPE/CB is made into small thin sheets, it is easy to fracture, restricting their application in the precise and compact modern electronic equipment that require good flexibility $[8,15]$. Therefore, it is urgent to impart carbon black-filled polyolefin composites with both good flexibility and considerable PTC intensity.

The incorporation of carbonous fillers into polymer composites is unfavorable for the flexibility [16-20]. It is reported that there are two methods of reducing the brittleness and improving the flexibility of conductive polymer composites: one is to reduce the amount of conductive filler 
needed to form the conductive network in the composite system, namely, reducing the percolation threshold [21]. The other is to introduce rubber or thermoplastic elastomer (TPE) into the composite system [9, 22, 23]. Liu et al. [9] melt blended styrene-ethylene-butylene-styrene (SEBS) with a graphene nanoplatelet- (GNP-) filled HDPE masterbatch. The results showed that the elongation at break of HDPE/GNP/SEBS blend increased with increasing concentration of the thermoplastic elastomer, reaching a maximum of more than $300 \%$. Meanwhile, it still exhibited certain selfregulating heating function. Wang and Cheng [23] compared the PTC effect of olefin block copolymer (OBC)/paraffin/graphite with that of low-density polyethylene (LDPE)/paraffin/graphite, finding that the composites with OBC had better flexibility than those with LDPE. The room temperature resistivity of the former was two orders of magnitude lower than the latter, but the problem is that the former showed a relatively lower PTC intensity.

Polymer blending influences PTC properties in three ways. First, some researchers found that different polymer matrix with different polymer crystallization behavior can exhibit different thermal volume expansion behavior and thus influence PTC behavior [24-26]. Luo et al. [25] found that ethyl vinyl acetate (EVA)/LDPE/CB have lower PTC intensity and lower temperature at the maximum of resistivity exists than LDPE/CB, which is believed to be the result of imperfection of crystalline regions between EVA and LDPE. Secondly, the blending of other polymer components forms the "sea island" effect or segregated structures to tune the conductive networks $[15,27,28]$. Zha et al. [21] fabricated a kind of nanocomposites with remarkably enhanced positive temperature coefficient by blending ultrahigh molecular weight polyethylene (UHMWPE) with polyvinylidene fluoride (PVDF). The PTC intensity of UHMWPE/PVDE/CB is higher than that of UHMWPE/CB, and the initial resistivity of UHMWPE/PVDE/CB is lower than that of UHMW$\mathrm{PE} / \mathrm{CB}$ for the volume exclusion effect of PVDF phase. The SEM images prove the existence of segregated structure and the preferential distribution of carbon filler in UHMWPE phase. Thirdly, the PTC intensity of PTC composites is directly positively related to thermal expansion coefficients of the matrix $[4,25,29]$.

Conclusively, the phase morphology can be tuned by polymer blending to impart composites with balanced and optimised electrical and mechanical properties [30, 31]. However, there still exist some problems such as low PTC intensity $[9,23]$. POE is a type of TPE synthesized by ethylene-octene random copolymerization, possessing the advantages of good thermal stability, good processability, and good flexibility. Blending POE into polyolefin-based PTC composites to improve the flexibility and PTC intensity has still not been systematically studied. In this paper, in the CB-filled HDPE masterbatch, HDPE and POE were meltblended in different ratios to tune the electrical and mechanical properties. Notably, the effects of $\mathrm{CB}$ content and POE content on the PTC behavior and flexibility were systematically investigated. Micro morphology and crystallization behavior are closely related to PTC properties. Thus, SEM was conducted to reveal phase morphology and filler distri- bution and DSC was conducted to research crystallization behavior. This kind of PTC composites is expected to be applied in fields that need good flexibility.

\section{Materials and Methods}

2.1. Raw Materials. The HDPE/CB masterbatch with trademark B2000, which is composed of $50 \mathrm{wt} \%$ HDPE and 50 wt.\% CB, was supplied by Guangdong Meilian New Material Co. Ltd. HDPE with trademark 8008 was supplied by Fujian United Petrochemical Co. Ltd., with a density of $0.955 \mathrm{~g} / \mathrm{cm}^{3}$ and a melt flow rate of $7.6 \mathrm{~g} / 10 \mathrm{~min}$. POE with trademark 8150 (a metallocene-catalysed copolymer of ethylene and $25.0 \mathrm{wt} . \% 1$-octene, with a density of $0.868 \mathrm{~g} / \mathrm{cm}^{3}$ and a melt flow rate of $0.5 \mathrm{~g} / 10 \mathrm{~min}$ ) was obtained from US Dow Chemical Company.

2.2. Sample Preparation. According to the preset formulas, the dried HDPE, HDPE/CB masterbatch, and POE were weighed. HDPE was first plasticated through a double-roll open mill with roll temperature of $130^{\circ} \mathrm{C}$ and roll distance of $0.5 \mathrm{~mm}$. After the plastication was completed, POE and HDPE/CB masterbatch were successively added and mixed for $6 \sim 8$ times triangle package and then lowered the roll distance to $0.1 \mathrm{~mm}$ and mixed them for another $4 \sim 6$ times triangle package. Finally, using a plate vulcanizer (QLBD350X2), all the blends were pressed into square sheets with a thickness of $1 \mathrm{~mm}$ under a pressure of $10 \mathrm{MPa}$ at $170^{\circ} \mathrm{C}$ for $10 \mathrm{~min}$ and cooled to room temperature for $3 \mathrm{~min}$ under the same pressure. For brevity, the formulations of HDPE-based composites were marked according to the loading of $\mathrm{CB}$ and POE.

\subsection{Characterization}

2.3.1. Measurement of Volume Resistivity-Temperature Curves. The sheets with a thickness of $1 \mathrm{~mm}$ were cut into straight sheets with dimensions of $75 \mathrm{~mm} \times 10 \mathrm{~mm} \times 1 \mathrm{~mm}$. In order to reduce the contact resistance, both ends of all samples were coated with $15 \mathrm{~mm}$ wide aluminum foils with effective conductive length of $46 \mathrm{~mm}$. The aluminum foils were compressed onto the sample with clips, and the electrodes were jointed onto the clips. The temperature was controlled by a constant temperature humidity chamber, varied from $20^{\circ} \mathrm{C}$ to $120^{\circ} \mathrm{C}$. After stabilizing the temperature at each point for $30 \mathrm{~min}$, the volume resistance of the samples was measured by using a resistance meter RM3554 (HIOKI). The volume resistivity can be calculated by the following formula:

$$
\rho=\frac{h b R}{l}=\frac{R}{46}
$$

where $\rho$ is the volume resistivity $(\Omega \cdot \mathrm{cm})$ and $h, b$, and $l$ are the thickness $(\mathrm{cm})$, width $(\mathrm{cm})$, and length $(\mathrm{cm})$, respectively. $R$ is the volumn resistance $(\Omega)$.

2.3.2. Tensile Properties. The straight sheet samples with dimensions of $1 \mathrm{~mm} \times 10 \mathrm{~mm} \times 75 \mathrm{~mm}$ were used to determine the tensile strength and elongation at break of the 
samples on an ZWICK universal material test machine (Z010) according to ASTM D412 A. The crosshead speed was $500 \mathrm{~mm} \cdot \mathrm{min}^{-1}$, and at least three samples were tested to obtain the average results.

2.3.3. Scanning Electron Microscopy (SEM). The samples were brittle-fractured by means of liquid nitrogen, and the fractured surfaces were sputtered with gold before observation. The phase morphology and filler distribution of samples were characterized with a scanning electron microscope EVO18 (SEM, Carl Zeiss Germany).

2.3.4. Differential Scanning Calorimetry (DSC). The melting behaviors of the composites were measured using an automatic differential scanning calorimetry DSCAQ (USA, TA Company). Under nitrogen atmosphere, $3 \sim 5 \mathrm{mg}$ samples were first treated with a heating-cooling cycle to eliminate the thermal history. Then, they were heated up to $180^{\circ} \mathrm{C}$ at a heating rate of $10^{\circ} \mathrm{C} / \mathrm{min}$ and held at $180^{\circ} \mathrm{C}$ for $5 \mathrm{~min}$ to obtain heating curves.

\section{Results and Discussion}

3.1. Electrical Properties of HDPE/CB and HDPE/POE/CB. The percolation threshold is defined as the critical concentration of $\mathrm{CB}$ particles to form a conductive network. Above the critical concentration, the resistivity of composites decreases significantly with increasing filler content. Keeping the percolation threshold as low as possible can contribute to the better flexibility of composites. Figure 1(a) shows the room temperature resistivity of both HDPE/CB and HDPE/$\mathrm{POE} / \mathrm{CB}$ (the mass fraction of POE is $18 \mathrm{wt} . \%$ ) as a function of the $\mathrm{CB}$ content (10 wt.\% 40 wt.\%). It was observed that with increasing loading of $\mathrm{CB}$, both samples exhibit sharply decreased volume resistivity. The room temperature resistivity of HDPE/CB decreases dramatically by about 5.3 orders of magnitude in the range of $\mathrm{CB}$ content from $20 \mathrm{wt} . \%$ to $25 \mathrm{wt} . \%$, while the room temperature resistivity of HDPE/POE/CB decreases dramatically by about 3.0 orders of magnitude in the range of $\mathrm{CB}$ content from $15 \mathrm{wt} . \%$ to $20 \mathrm{wt} . \%$, indicating that good conductive networks are formed in the concentration ranges. Classical percolation theory is suitable to describe the resistivity change of the composites by a power law:

$$
\rho \propto\left(\omega-\omega_{c}\right)^{t},
$$

where $\rho$ is the volume resistivity, $\omega$ is the mass fraction of $\mathrm{CB}, \omega_{c}$ is the percolation threshold, and $t$ is the critical exponent [30-32]. As shown in Figure 1(b), by fitting of experimental results with percolation law, the percolation threshold of HDPE/CB is calculated to be $22.5 \mathrm{wt} . \%$ and the percolation threshold of $\mathrm{HDPE} / \mathrm{POE} / \mathrm{CB}$ is calculated to be 16 wt.\%. HDPE/POE/CB has a lower percolation threshold than HDPE/CB, which means the incorporation of POE reduces the percolation threshold. Building segregated conductive structure enriches the conductive fillers in the interfacial regions and the percolation threshold of CPCs can be effectively reduced, which is also called exclusion and block effect [15, 31, 33-35]. Under the same CB content, the segregated structure formed by the POE phases in the matrix can bring about a denser conductive pathway, decreasing the resistance between $\mathrm{CB}$ particles, thus lowering the percolation threshold of HDPE/POE/CB. The segregated structure can be observed in the SEM images of HDPE/POE/CB with 10 wt.\% CB: Figures 2(a) and 2(b), in which the fibrous POE phase in red circles excludes CB aggregates into HDPE phase.

We compare results above with three CB-filled polyolefin composites from other references in Table 1. The percolation threshold of HDPE/CB is calculated to be $22.5 \mathrm{wt} . \%$ in this article, close to the percolation threshold of HDPE/CB (20wt.\%) studied in Reference [29]. The introduction of a second polymer matrix can help form segregated structure. In this article, POE phase shows the volume exclusion effect and $\mathrm{CB}$ is selectively located in HDPE phase, which decreased the percolation threshold to $16.0 \mathrm{wt} . \%$. Similar behaviors are seen in References [30,31], in which the percolation threshold of UHMWPE/PP/CB is $5.0 \mathrm{wt} . \%$ and the percolation threshold of HDPE/EVA/CB is $15.0 \mathrm{wt} . \%$.

The segregated structure can also decrease the resistivity of composites. According to Figure 1(a), when CB content is less than $25 \mathrm{wt} . \%$, the room temperature resistivity of $\mathrm{HDPE} / \mathrm{POE} / \mathrm{CB}$ is lower than that of HDPE/CB for the segregated structure. However, when $\mathrm{CB}$ content is more than $25 \mathrm{wt} . \%$, the room temperature resistivity of HDPE/POE/CB surpasses that of HDPE/CB. This is probably because when the $\mathrm{CB}$ content is high enough, $\mathrm{CB}$ particles will migrate into POE phase and destroy the segregated structure. The POE phase will act as barriers or diluents [9] of the conductive pathways, which will make the room temperature resistivity of HDPE/POE/CB higher than HDPE/CB. This can be seen in the SEM images of HDPE/POE/CB with $30 \mathrm{wt} . \% \mathrm{CB}$ : Figures 2(c) and 2(d).

3.2. The PTC Behaviors of HDPE/POE/CB with Various $C B$ Content and $P O E$ Content. PTC intensity reflects the significant degree of PTC effect of composites. Generally, the PTC effect is triggered by polymer phase transition. When the crystalline phase of semicrystalline polymer composites transforms to the amorphous phase, a significant thermal expansion occurs, increasing the interparticle distances of $\mathrm{CB}$, reducing the number of conductive paths, thus resulting in dramatically increased resistivity of the materials [37]. The calculation formula of PTC intensity is as follows:

$$
\text { PTC intensity }=\log \left(\frac{\rho_{\max }}{\rho_{\mathrm{RT}}}\right),
$$

where $\rho_{\mathrm{RT}}$ is the room temperature resistivity and $\rho_{\max }$ is the maximum resistivity.

Figure 3(a) presents the volume resistivity-temperature curves of HDPE/POE/CB composites. Setting the POE content as $18 \mathrm{wt} . \%$, as the $\mathrm{CB}$ content increases from $25 \mathrm{wt} . \%$ to $35 \mathrm{wt} . \%$, the whole resistivity-temperature curves move down, which means the resistivity gradually decreases as a result of increasing CB content [34]. The resistivity of each sample sharply increases by more than four orders of 


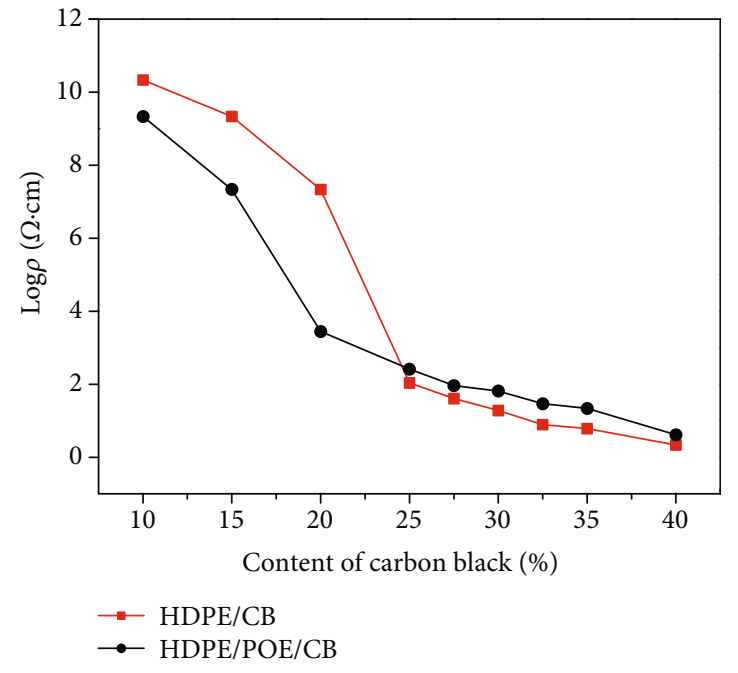

(a)

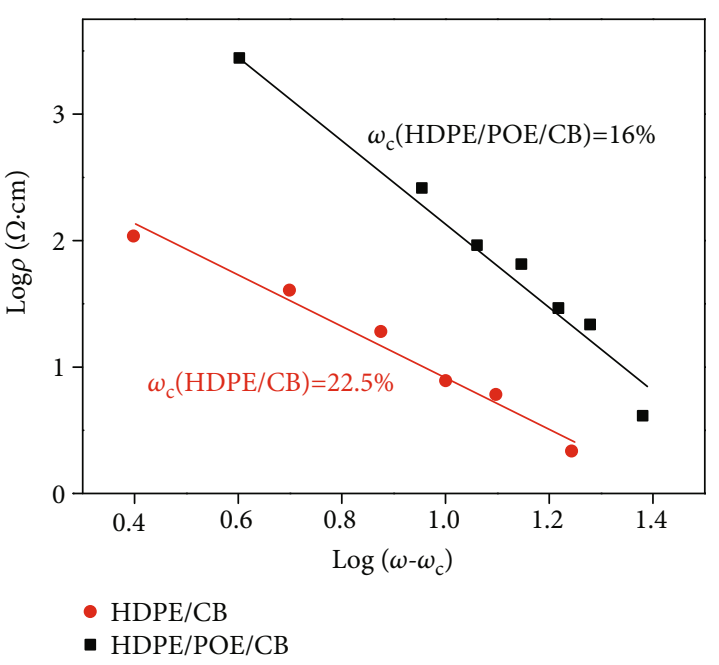

(b)

FIGURE 1: (a) Electrical conductivity as a function of the CB content; (b) fitting of experimental results with percolation law.

magnitude in the same temperature range from $90^{\circ} \mathrm{C}$ to $110^{\circ} \mathrm{C}$. The improvement of $\mathrm{CB}$ content has little effect on the PTC switching temperature. Figure $3(\mathrm{~b})$ shows that the PTC intensity fluctuates with increasing loading of CB but shows an overall descending trend. In general, the highest PTC intensity appears near the percolation threshold of CPCs $[15,18]$. When CB content is above the percolation threshold of $16 \mathrm{wt} . \%$, more conductive pathways have been formed throughout the matrix and the PTC intensity versus $\mathrm{CB}$ content shows a similar behavior to the resistivity versus $\mathrm{CB}$ content: the more $\mathrm{CB}$ is incorporated, the lower PTC intensity and resistivity are. Therefore, a descending trend of PTC intensity is seen. The nonuniformity of the samples gives rise to the experiment error and causes the PTC intensity fluctuation.

The PTC switching temperature typically corresponds to the melting temperature of the polymer [39]. The melting temperature of $\mathrm{POE}$ is about $61.1^{\circ} \mathrm{C}$ and $\mathrm{HDPE}$ is about $126.1^{\circ} \mathrm{C}$ as seen in Figure 4. The cocrystallization between HDPE and POE lowers melting temperature of the composites, which can be proved through DSC in Figure 5(b) and Table 2 [26]. As shown in Figure 3(c), as the POE content increases from 0 to $28 \mathrm{wt} . \%$, the dramatically increased resistivity occurs at lower temperature, which means the lower PTC switching temperature is obtained. Moreover, Figure 3(c) and Table 3 show that the resistivity of the composites gradually increases as the POE content increases. This is probably because when $\mathrm{CB}$ content is as high as $30 \mathrm{wt} . \%, \mathrm{CB}$ particles migrate into the POE phase and destroy the segregated structure. The POE phases act as barriers or diluents and decrease the number of the conductive pathways [9].

Besides, Figure 3(d) shows that the PTC intensity of the composites gradually increases from 6.10 to 8.51 . According to Table 3, the logarithm of resistivity change rate from $110^{\circ} \mathrm{C}$ to $120^{\circ} \mathrm{C}$ of the composites is 4.62 for the sample POE- $0 \%$ CB-30\% and the inclusion of POE (13 wt.\% 28 wt.\%) decreases the logarithm of resistivity change rate from $110^{\circ} \mathrm{C}$ to $120^{\circ} \mathrm{C}$ of each sample to 3.18 . However, the logarithm of resistivity change rate from $20^{\circ} \mathrm{C}$ to $110^{\circ} \mathrm{C}$ of the composites increases from 1.49 to 5.34 with increasing POE content. It can be concluded that the inclusion of POE can greatly increase the resistivity change rate of low temperature range from $20^{\circ} \mathrm{C}$ to $110^{\circ} \mathrm{C}$ and thus increase the PTC intensity across the whole temperature range. This is because POE phase has a much lower melting temperature with phase change that occurs at lower temperature. This causes higher thermal expansion coefficients within low temperature range from $20^{\circ} \mathrm{C}$ to $110^{\circ} \mathrm{C}$. The higher resistivity change rate of low temperature range can inhibit the overheating at the early stage, which is favorable for the safety of the PTC composites.

\subsection{Tensile Properties of HDPE/POE/CB with Various $C B$} Content and POE Content. Good flexibility allows PTC composites to be used in wearable electronic devices, soft robots, medical electronic equipment, and flexible electrodes [2]. To guarantee enough flexibility of HDPE/POE/CB, the dependence of tensile strength and elongation at break on the $\mathrm{CB}$ and $\mathrm{POE}$ content is investigated as shown in Figures 6(a) and 6(b). In Figure 6(a), fixing the POE content at $18 \mathrm{wt} . \%$, the tensile strength decreases from $18.8 \mathrm{MPa}$ to $10.0 \mathrm{MPa}$ and the elongation at break decreases from $1435 \%$ to $987 \%$ as the CB content increases from $15 \mathrm{wt} . \%$ to $35 \mathrm{wt} . \%$. This is because the addition of rigid particles $\mathrm{CB}$ into the composites improves the tensile modulus and has an adverse effect on the flexibility and stretchability [17]. Fixing the $\mathrm{CB}$ content at $30 \mathrm{wt} . \%$, Figure 6(b) shows that the addition of POE into the composites gradually enhances their flexibility. Although the tensile strength decreases with increasing proportion of POE, the elongation at break experienced a distinguished improvement especially when the POE content increases from 13 wt.\% to 18 wt.\%. A tough-brittle transition occurs at $18 \mathrm{wt} . \%$, and the flexibility of the blends sharply increases. This can be attributed to the inherent low crystalline and high flexibility of POE. When the POE content is above $13 \mathrm{wt} . \%$, the POE phase transforms from dispersed phase to continuous phase in the matrix, 


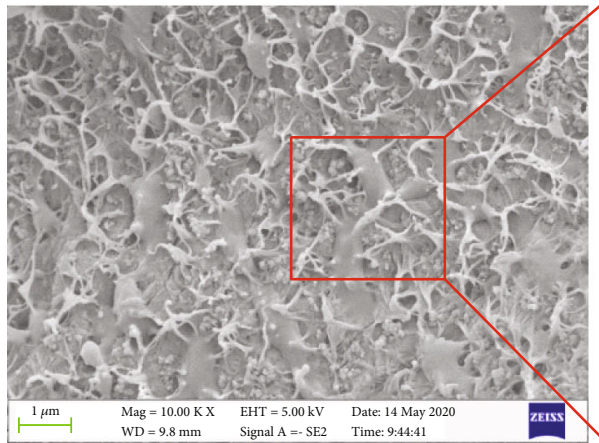

(a)

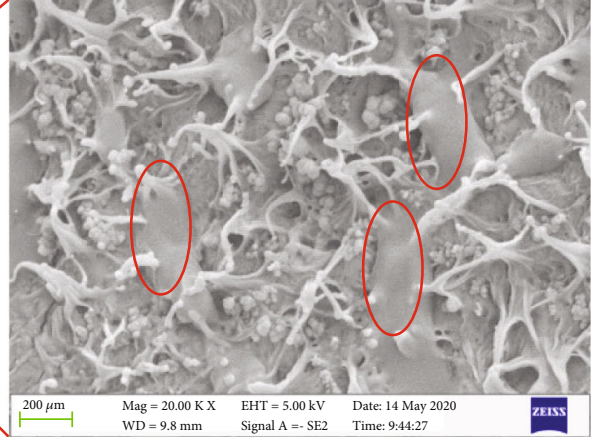

(b)

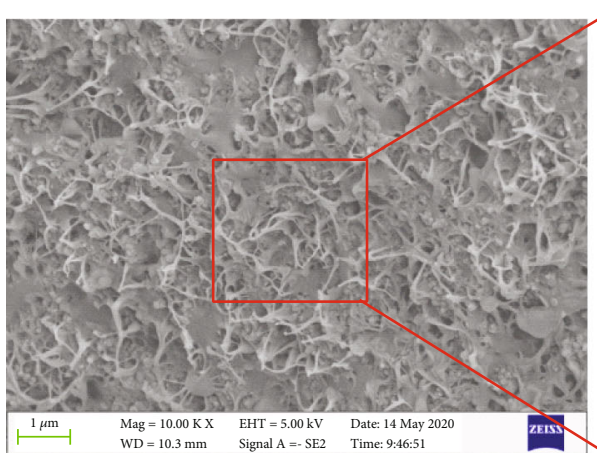

(c)

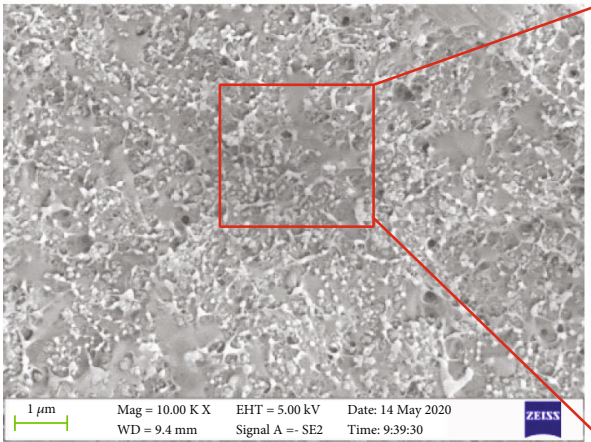

(e)

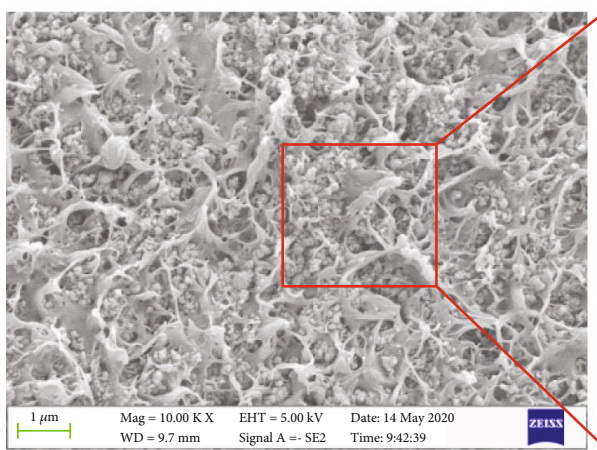

(g)

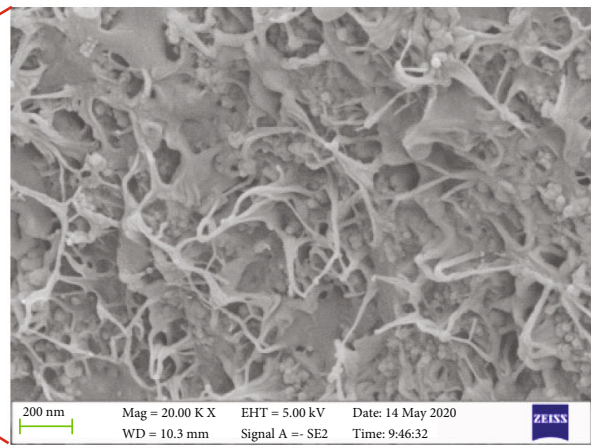

(d)

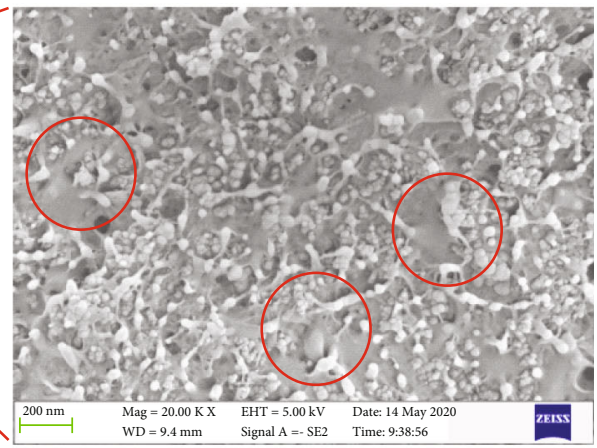

(f)

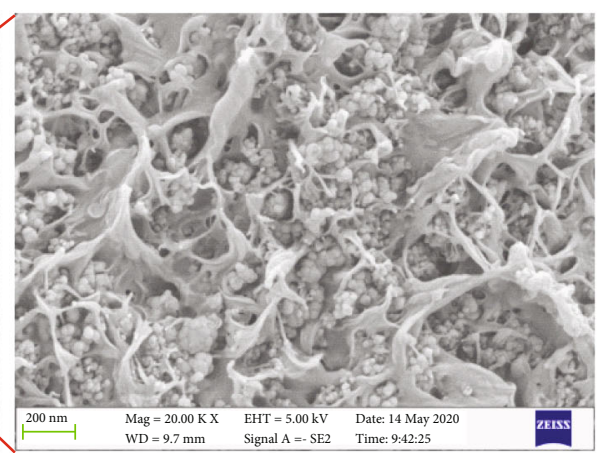

(h)

Figure 2: The POE content was fixed at $18 \mathrm{wt} . \%$, SEM images of HDPE/POE/CB with (a) 10 wt.\% and (c) 30 wt.\% CB. The CB content was fixed at $30 \mathrm{wt}$ \%, SEM images of HDPE/POE/CB with (e) $13 \mathrm{wt} . \%$ and (g) $23 \mathrm{wt} . \%$ POE. Images (b), (d), (f), and (h) are the amplification, respectively. 
TABLE 1: The comparison of percolation threshold and filler distribution of different polymer composites.

\begin{tabular}{lcrr}
\hline Components of polymer composites & Percolation threshold (wt.\%) & Main location of carbon black & References \\
\hline HDPE/CB & 22.5 & - & This article \\
HDPE/POE/CB & 16.0 & HDPE phase & This article \\
HDPE/CB & 20.0 & - & Reference [36] \\
UHMWPE/PP/CB & 5.0 & Interface and PP phase & Reference [37] \\
HDPE/EVA/CB & 15.0 & - & Reference [38] \\
\hline
\end{tabular}

"-_" means the related information is not mentioned in the related reference.

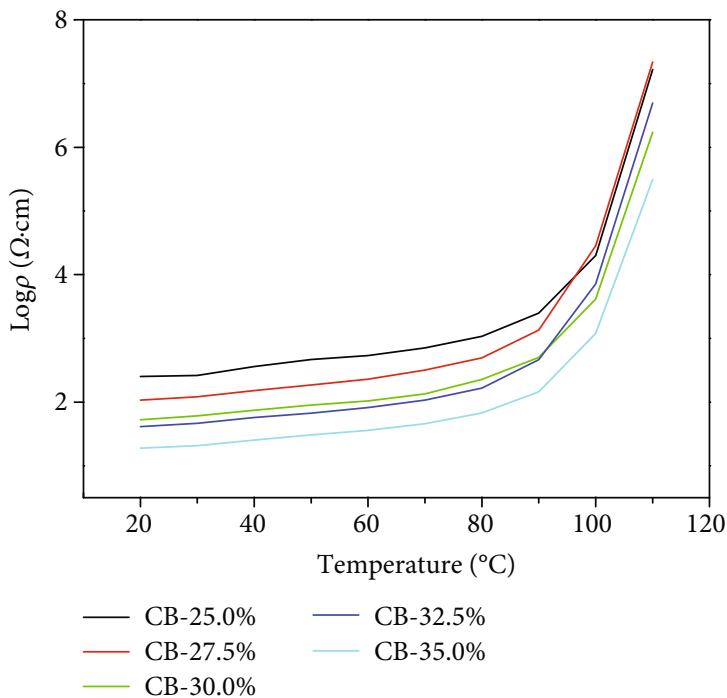

(a)

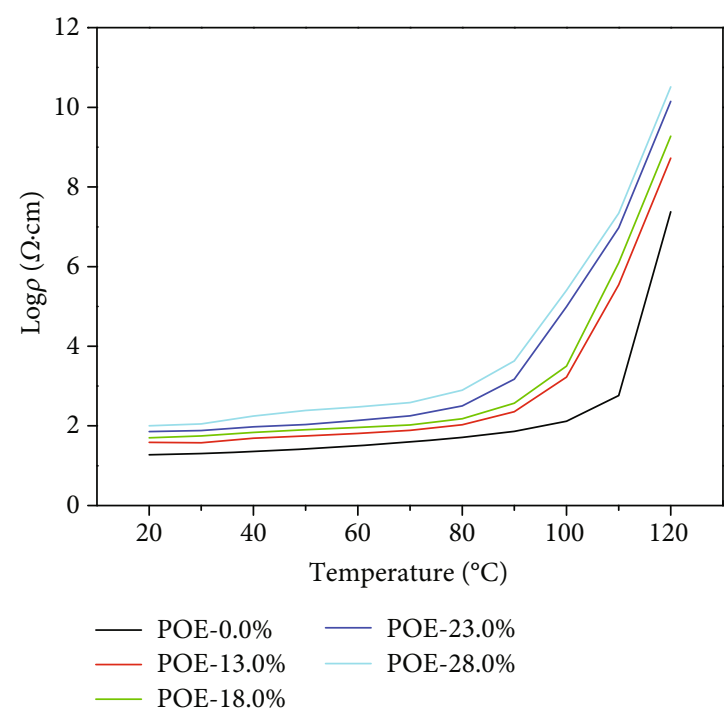

(c)

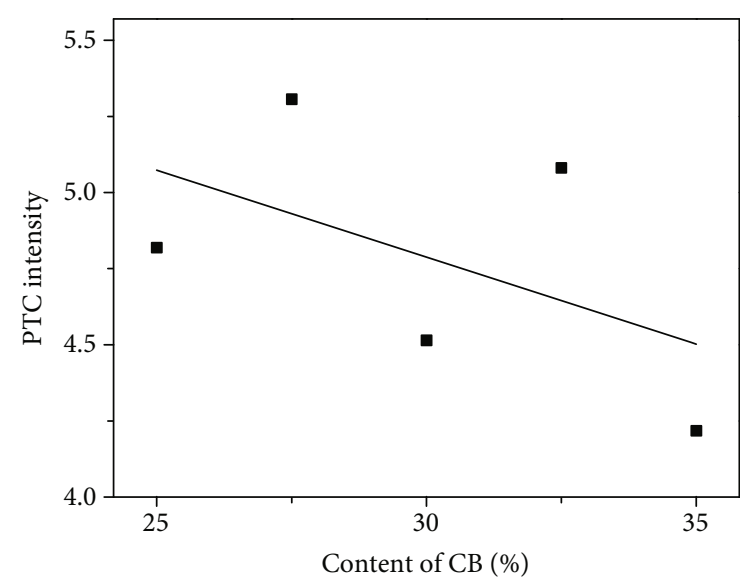

(b)

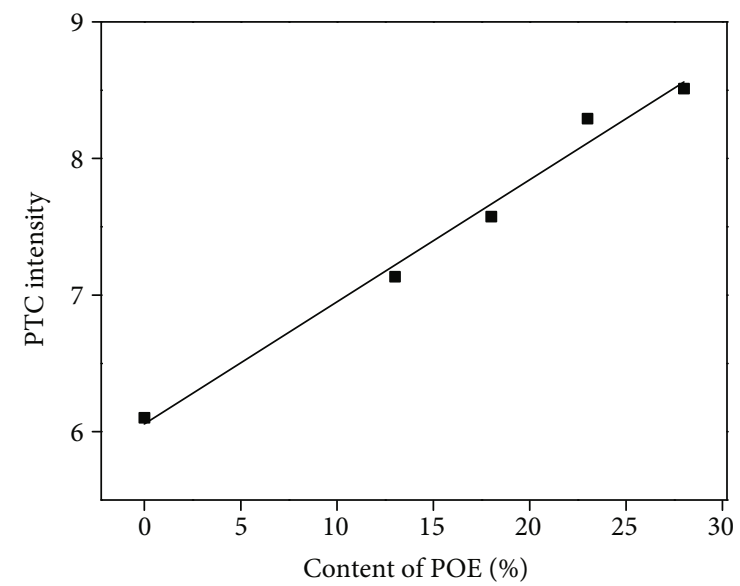

(d)

Figure 3: (a) The PTC behaviors of HDPE/POE/CB with various $\mathrm{CB}$ content (POE content is 18\%). (b) Plot of PTC intensity of $\mathrm{HDPE} / \mathrm{POE} / \mathrm{CB}$ with various $\mathrm{CB}$ content (POE content is 18\%). (c) The PTC behaviors of HDPE/POE/CB with various POE content (CB content is 18\%). (d) Plot of PTC intensity of HDPE/POE/CB with various POE content (CB content is $18 \%$ ).

which imparts the composites with elastomer-like properties. But at the same time, the inherent low tensile strength and the low degree of crystallinity of POE phase will cause the lower tensile strength of composites. These results fairly conform to the research of Liu and Qiu [40] and Paul and Kale [41]. They propose that the tough-brittle transition occurred at the $20 \mathrm{wt} . \% \sim 25 \mathrm{wt} . \%$ of POE in polypropylene/POE system. 


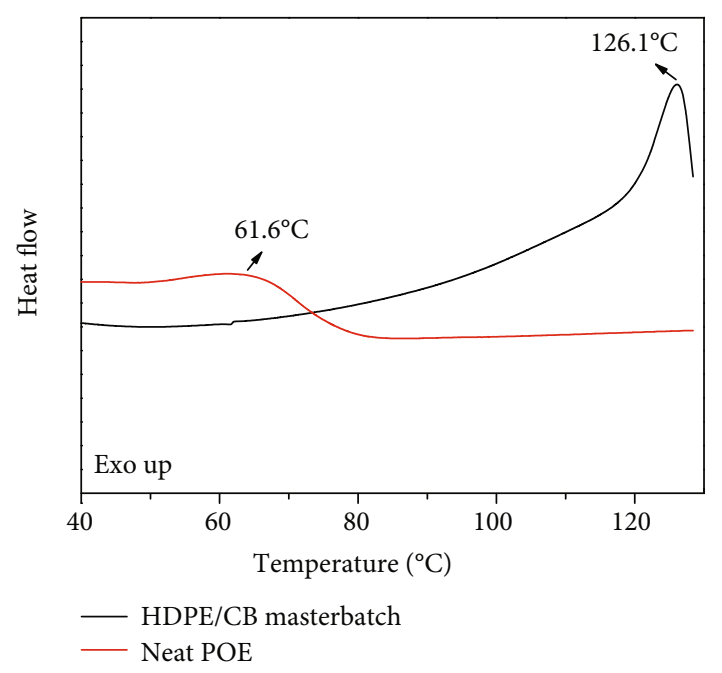

FIGURE 4: Plot of DSC analysis of HDPE/CB masterbatch and neat POE.

It is reported that as the rigid filler content increases, the degree of entanglement between the polymer and filler increases, which means the behavior of entanglement between the polymer and filler increases, while the $\mathrm{C}$ factor gradually decreases, which means a lower proficiency of the distribution of fillers and a lower effectiveness of the composites. Therefore, as the CB content increases from $15 \mathrm{wt} . \%$ to $35 \mathrm{wt} . \%$, the restricting effect of CB particles on the polymer chain mobility enhances. This can explain the decrease in the tensile strength and elongation at break of $\mathrm{HDPE} / \mathrm{POE} / \mathrm{CB}$ composites, as seen in Figure 6(a) [16-18, 42-44].

3.4. Phase Morphologies. The dispersion of CB particles across the composites is closely related to the electrical conductivity. Studying the dispersion of CB particles and the morphology of the composites is helpful for us to explain the conductive behavior. For comparison, first we take the SEM images of HDPE/POE/CB (the mass fraction of POE is $18 \mathrm{wt} . \%$ ) with different $\mathrm{CB}$ content of $10 \mathrm{wt} . \%$ and 30 wt.\%. Due to the same loading of POE, the fibrous POE phase with the same distribution density is evenly dispersed across the whole region. It can be seen in red circles in Figures 2(a) and 2(b) that when the CB content is $10 \mathrm{wt} . \%$, the fibrous POE phase excludes CB aggregates into HDPE phase, which constructs the segregated conductive network and increases the effective concentration of conductive $\mathrm{CB}$ particles, while in Figures 2(c) and 2(d) when the CB content is $30 \mathrm{wt} . \%, \mathrm{CB}$ particles evenly distribute across the whole region of matrix and the segregated conductive network is replaced by well-distributed conductive network. In this situation, the POE phase acts as barriers or diluents and decreases the number of the conductive pathways [45]. These SEM images can explain the electrical properties of HDPE/CB and HDPE/POE/CB: when the $\mathrm{CB}$ content is less than $25 \mathrm{wt} . \%$, the room temperature resistivity and the percolation threshold of $\mathrm{HDPE} / \mathrm{POE} / \mathrm{CB}$ is lower than that of HDPE/CB due to the segregated structure. However, when the CB content is more than $25 \mathrm{wt} . \%$, the room temperature resistivity of $\mathrm{HDPE} / \mathrm{POE} / \mathrm{CB}$ surpasses that of HDPE/CB for the barrier effect of the POE phase [45].

Moreover, we also compare the SEM images of $\mathrm{HDPE} / \mathrm{POE} / \mathrm{CB}$ (the mass fraction of $\mathrm{CB}$ is $30 \mathrm{wt} . \%$ ) with different POE content of $13 \mathrm{wt} . \%$ and $23 \mathrm{wt} . \%$, respectively, in Figures 2(e)-2(h). Under high CB content of $30 \mathrm{wt} . \%$, $\mathrm{CB}$ particles migrate into POE phase, evenly distributed across the whole region of matrix, which destroy the segregated structure. In this situation, the POE phase acts as barriers and cuts off the conductive pathways to lower the room temperature resistivity [9]. The dispersed phase is seen in red circles in Figure 2(f) when the POE content is $13 \mathrm{wt} . \%$, and the dispersed phase transforms into the continuous phase when the POE content reaches $23 \mathrm{wt} . \%$. The continuous phase has a more significant barrier effect than the dispersed phase. It can be concluded that as the POE content increases from 0 to $28 \mathrm{wt} . \%$, the barrier effect of the POE phase is gradually enhanced so the room temperature resistivity gradually increases. This kind of transformation of the phase morphologies can also explain the great improvement in elongation at break of $\mathrm{HDPE} /-$ $\mathrm{POE} / \mathrm{CB}$ as the POE content increases from $13 \mathrm{wt} . \%$ to 23 wt. $\%$.

3.5. Differential Scanning Calorimetry (DSC). Most of polymer PTC composites are semicrystalline. The heating of polymer PTC composites generally induces thermal expansion, especially around the melting temperature. The difference in thermal expansion coefficients between polymer matrix and carbon black will provide enough driving force and space condition for the migration of the $\mathrm{CB}$ particles and significantly affect the conductive network in the matrix. Consequently, the resistivity will sharply increase [25]. Accordingly, the study of the melting behaviors is necessary for us to deeply look into the PTC behaviors of the composites. Through DSC, the melting behavior of pure HDPE and its composites is present in Figures 5(a) and 5(b) and Table 2. Table 2 lists the melting peak temperature and crystalline degree of every sample.

From Figure 5(a) and Table 2, it is known that the melting peak temperature of the composites is between $131^{\circ} \mathrm{C}$ and $134^{\circ} \mathrm{C}$ after loading $\mathrm{CB}$ particles. Increasing the $\mathrm{CB}$ content has little effect on the melting peak temperature. This can explain why the PTC switching temperature remains the same in Figure 3(a). But it decreases the degree of crystallinity. The reason may be that rigid $\mathrm{CB}$ particles can partly hinder the movement the HDPE molecular chains, which has an adverse effect on the crystallization [46].

Figure 5(b) shows that as the POE content increases from 0 to 23 wt. $\%$, the variation of the melting peak temperature is also small, but a wide and weak melting peak appears at about $110^{\circ} \mathrm{C}$ (as seen in the red circle in Figure 5(b)). We believe that it is related to the melting behaviors of the cocrystallization between HDPE and POE. We have known that the melting temperature of 


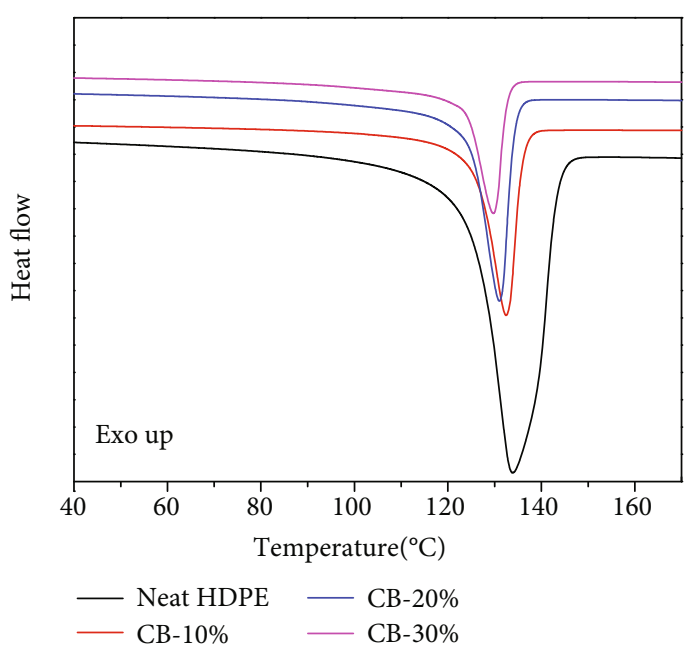

(a)

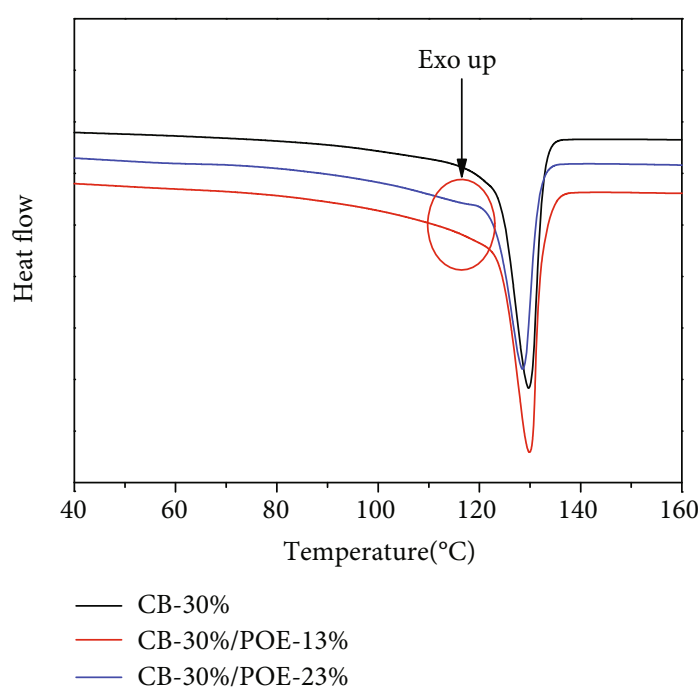

(b)

Figure 5: Plot of DSC analysis of HDPE/POE/CB composites with (a) different CB content and (b) different POE content.

TABLE 2: Thermal behavior of HDPE/POE/CB composites with various CB content and POE content.

\begin{tabular}{lccc}
\hline Sample & Melting peak temperature $\left({ }^{\circ} \mathrm{C}\right)$ & Melting enthalpy $(\mathrm{J} / \mathrm{g})$ & Crystalline degree $(\%)$ \\
\hline Neat HDPE & 133.9 & 211.3 & 73.4 \\
POE-0\%-CB-10\% & 132.5 & 167.4 & 64.6 \\
POE-0\%-CB-20\% & 131.0 & 144.5 & 62.7 \\
POE-0\%-CB-30\% & 129.7 & 113.1 & 56.1 \\
POE-13\%-CB-30\% & 130.0 & 78.48 & 48.7 \\
POE-23\%-CB-30\% & 128.5 & 58.65 & 44.3 \\
\hline
\end{tabular}

TABLE 3: The room temperature resistivity and resistivity change rate in different temperature ranges.

\begin{tabular}{lcccc}
\hline Sample & $\begin{array}{c}\text { Log (room temperature } \\
\text { resistivity) }(\Omega \cdot \mathrm{cm})\end{array}$ & $\begin{array}{c}\text { Log (resistivity change rate } \\
\left.\text { from } 20^{\circ} \mathrm{C} \text { to } 110^{\circ} \mathrm{C}\right)\end{array}$ & $\begin{array}{c}\text { Log (resistivity change rate } \\
\left.\text { from } 110^{\circ} \mathrm{C} \text { to } 120^{\circ} \mathrm{C}\right)\end{array}$ & $\begin{array}{c}\text { PTC intensity } \\
\text { POE-0\%-CB-30\% }\end{array}$ \\
POE-13\%-CB-30\% & 1.28 & 1.49 & 4.62 & 3.18 \\
POE-18\%-CB-30\% & 1.59 & 3.96 & 3.18 & 7.13 \\
POE-23\%-CB-30\% & 1.70 & 4.40 & 3.18 & 3.57 \\
POE-28\%-CB-30\% & 1.86 & 5.12 & 3.18 \\
\hline
\end{tabular}

POE is about $61.1^{\circ} \mathrm{C}$ and that of HDPE is about $126.1^{\circ} \mathrm{C}$. The HDPE polymer chain and the POE polymer chain entangle each other to form the cocrystallization. The cocrystallization between HDPE and POE lowers the temperature range of melting transition of the composites [26]. This can explain why the PTC switching temperature moves to lower temperature. Table 2 shows that the crystalline degree decreases from $56.1 \%$ to $44.3 \%$ with increasing POE content. As reported by Liu et al. [2], PTC intensity is not always proportional to the crystalline degree of PTC composites. In fact, it is also related to thermal expansion coefficients of the matrix $[4,25,29]$.
Although the inclusion of POE to a certain extent decreases the crystalline degree of PTC composites, it imparts the composites with higher thermal expansion coefficients because of the inherent higher thermal expansion coefficients of POE than HDPE. Therefore, the conductive pathways experience more severe destruction during heating process and the PTC intensity tends to be higher. This conclusion is consistent with the conclusion in section 3.2: the inclusion of POE can greatly increase the resistivity change rate of low temperature range and thus increase the PTC intensity across the whole temperature range. 


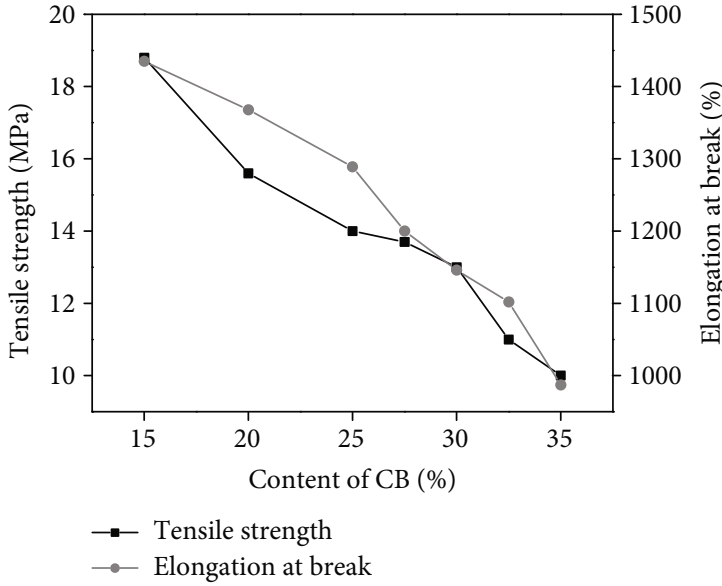

(a)

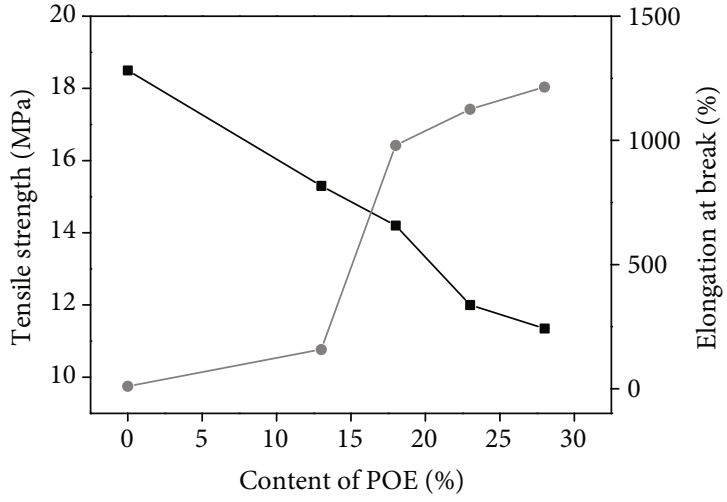

(b)

Figure 6: The POE content was fixed at 18 wt.\%, (a) shows the tensile properties of HDPE/POE/CB with various CB content; the CB content was fixed at $30 \mathrm{wt} . \%$, (b) shows the tensile properties of HDPE/POE/CB (30 wt.\%) with various POE content.

\section{Conclusions}

To gain balanced electrical and mechanical properties in carbon black-filled polyolefin composites, we introduced POE into the HDPE/CB composites and investigated the effect of the POE and $\mathrm{CB}$ content on the percolation threshold, room temperature resistivity, PTC behavior, and tensile properties. Combined with SEM images and DSC, we researched the phase morphology, filler dispersion, and crystallization behavior of the flexible PTC composites in detail. We tried to explain the electric and mechanical properties with micro morphology and crystallization behavior. It is found that the incorporation of POE decreases the percolation threshold of conductive $\mathrm{CB}$ particles. Increasing POE content can not only bring about the higher room temperature resistivity for its barrier effect but also cause the lower PTC switching temperature and the higher resistivity change rate within low temperature range. The higher resistivity change rate of low temperature range brings about the higher PTC intensity. It is believed that higher resistivity change rate of low temperature range can inhibit the overheating at the early stage, which is favorable for the safety of the PTC materials. When the POE content increases from $13 \mathrm{wt} . \%$ to $18 w t . \%$, the elongation at break of HDPE/POE/CB (the mass fraction of $\mathrm{CB}$ is $30 \mathrm{wt} . \%$ ) improves from $158 \%$ to 980\%, showing excellent flexibility. This novel PTC material can be expected to be utilized in cases that require enough flexibility. This work also provides a possible direction for the development new types of highperformance flexible PTC composites.

\section{Data Availability}

The experimental data used to support the findings of this study are available on request from the first author, who can be contacted at psfxue@scut.edu.cn.

\section{Conflicts of Interest}

The authors declare that they have no conflicts of interest.

\section{Acknowledgments}

The authors would like to thank Guangzhou Tachibana Electronic Co., Ltd. for funding and supporting this research.

\section{References}

[1] M. B. Heaney, "Resistance-expansion-temperature behavior of a disordered conductor-insulator composite," Applied Physics Letters, vol. 69, no. 17, pp. 2602-2604, 1996.

[2] Y. Liu, H. Zhang, H. Porwal, J. J. C. Busfield, T. Peijs, and E. Bilotti, "Pyroresistivity in conductive polymer composites: a perspective on recent advances and new applications," Polymer International, vol. 68, no. 3, pp. 299-305, 2019.

[3] P. Kar and B. B. Khatua, "PTCR characteristics of polycarbonate/nickel-coated graphite-based conducting polymeric composites in presence of poly(caprolactone)," Polymer Composites, vol. 32, no. 5, pp. 747-755, 2011.

[4] P. Kar and B. B. Khatua, "Highly reversible and repeatable PTCR characteristics of PMMA/Ag-coated glass bead composites based on CTE mismatch phenomena," Polymer Engineering and Science, vol. 51, no. 9, pp. 1780-1790, 2011.

[5] A. Kono, K. Shimizu, H. Nakano et al., "Positive-temperaturecoefficient effect of electrical resistivity below melting point of poly(vinylidene fluoride) (PVDF) in $\mathrm{Ni}$ particle-dispersed PVDF composites," Polymer, vol. 53, no. 8, pp. 1760-1764, 2012.

[6] J.-H. Lee, S. K. Kim, and N. H. Kim, "Effects of the addition of multi-walled carbon nanotubes on the positive temperature coefficient characteristics of carbon-black-filled high-density polyethylene nanocomposites," Scripta Materialia, vol. 55, no. 12, pp. 1119-1122, 2006.

[7] Y. Li, H. Zhang, Y. Liu et al., "Synergistic effects of spraycoated hybrid carbon nanoparticles for enhanced electrical and thermal surface conductivity of CFRP laminates," 
Composites Part a-Applied Science and Manufacturing, vol. 105, pp. 9-18, 2018.

[8] Y. Liu, H. Zhang, H. Porwal et al., "Universal control on pyroresistive behavior of flexible self-regulating heating devices," Advanced Functional Materials, vol. 27, no. 39, 2017.

[9] Y. Liu, H. Zhang, H. Porwal et al., "Tailored pyroresistive performance and flexibility by introducing a secondary thermoplastic elastomeric phase into graphene nanoplatelet (GNP) filled polymer composites for self-regulating heating devices," Journal of Materials Chemistry C, vol. 6, no. 11, pp. 27602768, 2018.

[10] L. Lu, X. Han, J. Li, J. Hua, and M. Ouyang, "A review on the key issues for lithium-ion battery management in electric vehicles," Journal of Power Sources, vol. 226, pp. 272-288, 2013.

[11] M. Kise, S. Yoshioka, K. Hamano et al., "Development of new safe electrode for lithium rechargeable battery," Journal of Power Sources, vol. 146, no. 1-2, pp. 775-778, 2005.

[12] D. Deng, "Li-ion batteries: basics, progress, and challenges," Energy Science \& Engineering, vol. 3, no. 5, pp. 385-418, 2015.

[13] J. Kim, J. Oh, and H. Lee, "Review on battery thermal management system for electric vehicles," Applied Thermal Engineering, vol. 149, pp. 192-212, 2019.

[14] S. M. Sun, X. Y. Zhang, and M. Q. Yang, "Lithium ion battery efficient thermal management numerical simulation research," Applied Mechanics and Materials, vol. 672-674, pp. 646-651, 2014.

[15] Y. Qin, X. Haiping, Q. Houtian et al., "Preparation and PTC properties of HIPS/HDPE/CB composites," Chemical Journal Of Chinese Universities-Chinese, vol. 39, no. 6, pp. 13051310, 2018.

[16] A. K. Pandey, T. Pal, R. Sharma, and K. K. Kar, "Study of matrix-filler interaction through correlations between structural and viscoelastic properties of carbonous-filler/polymermatrix composites," Journal of Applied Polymer Science, vol. 137, no. 27, article 48660, 2020.

[17] A. K. Pandey, R. Kumar, V. S. Kachhavah, and K. K. Kar, "Mechanical and thermal behaviours of graphite flakereinforced acrylonitrile-butadiene-styrene composites and their correlation with entanglement density, adhesion, reinforcement and C factor," RSC Advances, vol. 6, no. 56, pp. 50559-50571, 2016.

[18] R. Kumar, K. K. Kar, and K. Dasgupta, "Enhanced electrical, mechanical, and viscoelastic properties of carbon-carbon composites using carbon nanotubes coated carbon textile as reinforcement," Journal of Composite Materials, vol. 55, no. 13, pp. 1733-1748, 2021.

[19] A. K. Pandey, K. Singh, and K. K. Kar, "Thermo-mechanical properties of graphite-reinforced high-density polyethylene composites and its structure-property corelationship," Journal of Composite Materials, vol. 51, no. 12, pp. 1769-1782, 2017.

[20] R. Kumar, K. K. Kar, and K. Dasgupta, "Superior electrical, mechanical and viscoelastic properties ofCNTscoated carbon textile reinforced phenolic composite forhighperformancestructural applications," Journal of Applied Polymer Science, vol. 138, no. 10, p. 49968, 2021.

[21] J.-W. Zha, W. K. Li, R. J. Liao, J. Bai, and Z. M. Dang, "High performance hybrid carbon fillers/binary-polymer nanocomposites with remarkably enhanced positive temperature coefficient effect of resistance," Journal of Materials Chemistry A, vol. 1, no. 3, pp. 843-851, 2013.
[22] T. Li, L. F. Ma, R. Y. Bao et al., "A new approach to construct segregated structures in thermoplastic polyolefin elastomers towards improved conductive and mechanical properties," Journal of Materials Chemistry A, vol. 3, no. 10, pp. 54825490, 2015.

[23] R. J. Wang and W. L. Cheng, "A novel flexible room temperature positive temperature coefficient material for thermal management," Advanced Composites and Hybrid Materials, vol. 2, no. 1, pp. 83-92, 2019.

[24] Y. P. Mamunya, Y. V. Muzychenko, E. V. Lebedev et al., "PTC effect and structure of polymer composites based on polyethylene/polyoxymethylene blend filled with dispersed iron," Polymer Engineering and Science, vol. 47, no. 1, pp. 34-42, 2007.

[25] Y. L. Luo, G. Wang, B. Zhang, and Z. Zhang, "The influence of crystalline and aggregate structure on PTC characteristic of conductive polyethylene/carbon black composite," European Polymer Journal, vol. 34, no. 8, pp. 1221-1227, 1998.

[26] P. Zhang and B.-B. Wang, "Positive temperature coefficient effect and mechanism of compatible LLDPE/HDPE composites doping conductive graphite powders," Journal of Applied Polymer Science, vol. 135, no. 27, 2018.

[27] J. Y. Feng and C. M. Chan, "Carbon black-filled immiscible blends of poly(vinylidene fluoride) and high density polyethylene: the relationship between morphology and positive and negative temperature coefficient effects," Polymer Engineering and Science, vol. 39, no. 7, pp. 1207-1215, 1999.

[28] A. Rybak, G. Boiteux, F. Melis, and G. Seytre, "Conductive polymer composites based on metallic nanofiller as smart materials for current limiting devices," Composites Science and Technology, vol. 70, no. 2, pp. 410-416, 2010.

[29] J. F. Zhang, Q. Zheng, Y. Q. Yang, and X. S. Yi, "High-density polyethylene/carbon black conductive composites. II. Effect of electron beam irradiation on relationship between resistivitytemperature behavior and volume expansion," Journal of Applied Polymer Science, vol. 83, no. 14, pp. 3117-3122, 2002.

[30] H. Deng, L. Lin, M. Ji, S. Zhang, M. Yang, and Q. Fu, "Progress on the morphological control of conductive network in conductive polymer composites and the use as electroactive multifunctional materials," Progress in Polymer Science, vol. 39, no. 4, pp. 627-655, 2014.

[31] L. Xie and Y. Zhu, "Tune the phase morphology to design conductive polymer composites: a review," Polymer Composites, vol. 39, no. 9, pp. 2985-2996, 2018.

[32] C. S. Ha, S. J. Huang, and J. K. Lee, "Polymeric positivetemperature-coefficient materials: dynamic curing effect," Colloid and Polymer Science, vol. 282, no. 6, pp. 575-582, 2004.

[33] N. Ning, S. Li, H. Wu et al., "Preparation, microstructure, and microstructure-properties relationship of thermoplastic vulcanizates (TPVs): A review," Progress in Polymer Science, vol. 79, pp. 61-97, 2018.

[34] H. C. Tian, M. Tian, H. Zou, Z. Dang, and L. Zhang, "Special electrical conductivity of carbon black-filled two-phased thermoplastic vulcanizates," Journal of Applied Polymer Science, vol. 117, no. 2, pp. 691-699, 2010.

[35] A. de Alencar Padua Gabino, B. G. Soares, and A. A. Silva, "Attaining low percolation threshold in conductive polypropylene/nitrile rubber thermoplastic vulcanizates using carbon nanotube," Journal of Applied Polymer Science, vol. 138, no. 7 , article $49857,2021$.

[36] T. Jeevananda, Siddaramaiah, and J. Hee Lee, "Fabrication of carbon black/HDPE/polyaniline functionalized multi-walled 
carbon nanotube composites for enhancing PTC characteristics," Materials Today-Proceedings, vol. 5, no. 10, pp. 2089020898, 2018.

[37] Q. Li, S. Basavarajaiah, N. H. Kim, S. B. Heo, and J. H. Lee, "Synergy effect of hybrid fillers on the positive temperature coefficient behavior of polypropylene/ultra-high molecular weight polyethylene composites," Journal of Applied Polymer Science, vol. 116, no. 1, pp. 116-124, 2010.

[38] J. F. Zhang, Q. Zheng, Y. Q. Yang, and X. S. Yi, "High-density polyethylene/carbon black conductive composites. I. Effect of $\mathrm{CB}$ surface modification on its resistivity-temperature behavior," Journal of Applied Polymer Science, vol. 83, no. 14, pp. 3112-3116, 2002.

[39] L. Chen and J. M. Zhang, "Designs of conductive polymer composites with exceptional reproducibility of positive temperature coefficient effect: a review," Journal of Applied Polymer Science, vol. 138, no. 3, article 49677, 2021.

[40] G. Y. Liu and G. X. Qiu, "Study on the mechanical and morphological properties of toughened polypropylene blends for automobile bumpers," Polymer Bulletin, vol. 70, no. 3, pp. 849-857, 2013.

[41] S. Paul and D. D. Kale, "Impact modification of polypropylene copolymer with a polyolefinic elastomer," Journal of Applied Polymer Science, vol. 76, no. 9, pp. 1480-1484, 2000.

[42] P. Paik and K. K. Kar, "Thermal degradation kinetics and estimation of lifetime of polyethylene particles: Effects of particle size," Materials Chemistry and Physics, vol. 113, no. 2-3, pp. 953-961, 2009.

[43] C. J. Hsu, L. W. Chang, S. Y. Miao, and J. T. Lue, "High molecular weight polyethylene nanospheres: synthesis, physical and mechanical Properties-Second harmonic generation," Journal of Nanoscience and Nanotechnology, vol. 8, no. 6, pp. 2979-2982, 2008.

[44] A. Tharayil, S. Banerjee, and K. K. Kar, "Dynamic mechanical properties of zinc oxide reinforced linear low density polyethylene composites," Materials Research Express, vol. 6, no. 5, 2019.

[45] T.-N. Yue, Y. N. Gao, Y. Wang et al., "Processingtemperaturedependentdistribution ofmultiwallcarbon nanotube in poly(ethylene-co-1-octene)/high density polyethylene for electrical conductivity and microwave shielding enhancement," Polymer Composites, vol. 42, no. 3, pp. 1396-1406, 2021.

[46] J.-Z. Liang and Q.-Q. Yang, "Effects of carbon black content and size on conductive properties of filled high-density polyethylene composites," Advances in Polymer Technology, vol. 37, no. 6, pp. 2238-2245, 2018. 